NISTIR 6456

\title{
Certification of the Relative Molecular Mass and the Intrinsic Viscosity of SRM 2887, a Polyethylene of Narrow Molecular Mass Distribution
}

\author{
C. M. Guttman, J. R. Maurey, W.R. Blair, and C.R. Schultheisz \\ Polymers Division \\ NIST \\ Gaithersburg, MD 20899
}

Certain commercial materials and equipment are identified in this paper in order to specify adequately the experimental procedure. In no case does such identification imply recommendation or endorsement by the National Institute of Standards and Technology, nor does it imply necessarily the best available for the purpose.

According to ISO 31-8, the term "Molecular Weight" has been replaced by Relative Molecular Mass, symbol $M_{\mathrm{r}}$. Thus, if this nomenclature and notation were followed in this publication, one should write $M_{\mathrm{r}, \mathrm{w}}$ instead of the historically conventional $\mathrm{M}_{\mathrm{w}}$ for the weight average molecular weight with similar changes for $\mathrm{M}_{\mathrm{n}}, \mathrm{M}_{\mathrm{z}}$, and $\mathrm{M}_{\mathrm{v}} . \mathrm{M}_{\mathrm{w}}$ would be called the "Mass Average Relative Molecular Mass." The conventional notation, rather than the ISO notation, has been used in this publication.

Final report prepared for the sponsors, the NIST Standard Reference Materials Program (SRMP). 


\begin{abstract}
The certification of a polyethylene standard reference material, SRM 2887, is described. The $\mathrm{M}_{\mathrm{w}}$ of SRM 2887 by light scattering was determined to be $196.4 \times 10^{+3} \mathrm{~g} / \mathrm{mol}$ with a sample standard deviation of $6.6 \times 10^{+3} \mathrm{~g} / \mathrm{mol}$. A combined expanded uncertainty for this light scattering $\mathrm{M}_{\mathrm{w}}$ determination, including systematic and random uncertainties, was estimated to be $13.7 \times 10^{+3}$ $\mathrm{g} / \mathrm{mol}$. The intrinsic viscosity of SRM 2887 , by solution viscosity, in 1,2, 4-trichlorobenzene was determined to be $276.9 \mathrm{~mL} / \mathrm{g}$ with a sample standard deviation of $2.5 \mathrm{~mL} / \mathrm{g}$.. A combined expanded uncertainty for this intrinsic viscosity determination was 3.1 $\mathrm{mL} / \mathrm{g}$. The bottle-to-bottle variation of the SRM was checked by size exclusion chromatography (SEC) and found to be negligible.
\end{abstract}




\subsection{Introduction}

This report describes the certification of the $\mathrm{M}_{\mathrm{w}}$ by light scattering and intrinsic viscosity (often called the limiting viscosity number [1]) in 1,2,4-trichlorobenzene (TCB) at $130{ }^{\circ} \mathrm{C}$ of a linear polyethylene, SRM 2887. The material was obtained from fractionating SRM 1475, as described previously [2]. In the early 1970's, some of this fractionated material was used in the preparation of SRM 1482, SRM 1483, and SRM 1484. Other fractions from the separation had been stored in the Polymers Division in the intervening years. From this material three new narrow mass fraction SRMs are being certified. This reports describes the cleanup, the $\mathrm{M}_{\mathrm{w}}$ by light scattering and the intrinsic viscosity measurements on one of these fractions, a moderate molecular mass polyethylene. Bottle-to-bottle homogeneity on the final packaged material was determined by size exclusion chromatography (SEC).

\subsection{Preparation, Bottling, and Handling of SRM 2887}

\subsection{Preparation of the SRM}

The $\mathrm{M}_{\mathrm{w}}$ standard, SRM 2887, is a fraction of polyethylene SRM 1475. The fractionation was described in reference [2]. Fractions of SRM 1475, originally identified as LEA-4 and LEA-7, that had nearly the same SEC trace, were combined. This provided sufficient material for producing SRM 2887. The fractions contained fine powders, larger aggregates and some dirt particles. Also evident was a slight yellowing of the polymer. It was evident that these fractions needed to be cleaned and purified by recrystallization from solution prior to certification. Details of the recrystallization procedure and apparatus are given in Appendix I of reference [3].

Subsequent to recrystallization from solution as fine powders, the dry material was sieved together through a sieve with $1.65 \mathrm{~mm}$ openings (C E Tyler, Mentor Ohio, 10 meshes to the inch) and then well mixed in a $30 \mathrm{~cm}$ x $50 \mathrm{~cm}$ stainless steel tray. SEC was performed on samples taken from different positions in this tray to confirm the adequacy of mixing. After SEC samples were removed, the contents of the tray were sent to the NIST Standard Reference Materials Program (SRMP) for packaging.

\subsection{Bottling and Sampling of SRM 2887}

Of the approximately $240 \mathrm{~g}$ of purified material approximately $180 \mathrm{~g}$ was packaged in about 590 vials containing about $0.3 \mathrm{~g}$ each. In the following report, the containers holding SRM 2887 will be referred to as vials. The additional polymer was divided into two lots designated division 1 supply and division 2 supply. These large lot samples were used to supply some of the material used in the light scattering and intrinsic viscosity measurements. Prior to the use of material from these division supply lots, however, we showed that these samples were identical to the material in the vials. (See section 2.3).

The entire set of SRM 2887 vials was divided into 14 subsets of 41 or 42 vials. One vial was 
randomly selected from each subset of SRM 2887 for homogeneity testing. The first and last bottled vials were also taken. These vials and the two division supply lots were used in the SEC homogeneity testing described below. All these materials were used in the light scattering determinations and intrinsic viscosity determinations described in later sections

\subsection{Homogeneity Testing}

Homogeneity testing was accomplished using SEC. In this study, a Waters 150-C ALC/GPC Liquid Chromatograph (Waters Corp., Milford, MA) with a differential refractive index (DRI) detector and three Waters styragel columns, HT-6, HT-4, and HT-3, were used. The chromatograms were taken at a $0.8 \mathrm{~mL} / \mathrm{min}$ solvent flow rate. The injector and column compartments of the Waters 150-C ALC/GPC were controlled at $130{ }^{\circ} \mathrm{C}$ for all measurements. The solvent, 1,2,4-trichlorobenzene (TCB), was obtained from Aldrich Chemical (1,2,4trichlorobenzene, 99+\%, spectrophotometric grade, Aldrich Chemical, Milwaukee, WI) and used as received. Santonox (5-tert-Butyl-4-hydroxy-2-methylphenyl sulfide), also obtained from Aldrich Chemical, was added to the solvent at about $0.1 \mathrm{~g} / \mathrm{L}$ as an antioxidant.

Vials of SRM 2887 were obtained from SRMP as described above. The polymer in the two division supply lots was also included in this test. A mass of $1.3 \mathrm{mg}$ to $2.4 \mathrm{mg}$ of the polyethylene was weighed into the Waters autosampler bottle along with $4 \mathrm{~mL}$ of solvent yielding a concentration of approximately $0.6 \mathrm{~g} / \mathrm{L}$. Hexadecane, at $0.03 \mathrm{~mL} / \mathrm{L}$, was added to the solutions of polymer and solvent as a marker to indicate the reproducibility of the solvent volume delivered by the SEC pump for all measurements. Each autosampler bottle was heated to $150{ }^{\circ} \mathrm{C}$ in an oven for about $1.5 \mathrm{~h}$ and the solution was shaken at frequent intervals to aid the dissolution. The autosampler bottles were placed in the Waters 150-C ALC/GPC injection compartment held at $130{ }^{\circ} \mathrm{C}$. Chromatograms were then run with these solutions.

Solutions were prepared from each vial of SRM 2887 sample population and from each of the division supply lots. Two solutions were prepared from each vial selected from those received from SRMP and four solutions were prepared from each division supply lot. For SRM 2887, this resulted in 40 solutions to be tested. The order used to run the solutions was randomized following the method described in section 1-4 of the handbook by Natrella [4]. Two injections were made from each solution. All chromatographic data were obtained during a five-day period, with 10 solutions measured per day.

After baseline subtraction, the SEC chromatograms were normalized to unit peak height and compared initially by overlaying to determine if there were visible differences outside the noise. The chromatograms from different solutions all superimposed on each other. This preliminary comparison showed that polymer samples taken from all the vials produced identical chromatograms. Further statistical analysis of the chromatograms is discussed in Section 2.3.1 


\subsubsection{Statistical Method to Compare Chromatograms}

\subsubsection{Match Factor}

In previous SEC studies on SRM homogeneity, the match factor was used to compare one chromatogram to all others [5]. The match factor is a correlation coefficient between one chromatogram and another. The match factor is defined by Huber[6] as

$$
\text { Match Factor }=10^{3}\left\{3 x^{*} y-\left(3 x^{*} 3 y\right) / p\right\}^{2} /\left[\left\{3 x^{2}-3 x * 3 x / p\right\}\left\{3 y^{2}-3 y * 3 y / p\right\}\right]
$$

The values $\mathrm{x}$ and $\mathrm{y}$ are the measured signal in the first and second chromatograms, respectively, at the same time in the chromatograms; $p$ is the number of data points. The sums are taken over all data points.

At the extremes, a match factor of zero indicates no match and 1000 indicates identical chromatograms. Generally, values above 990 indicate that the chromatograms are similar. Values between 900 and 990 indicate there is some similarity, but the result should be interpreted with care. All values below 900 are interpreted to mean that the chromatograms are different [6,7]. The method we describe here has been used previously [8]. We obtained the match factor of the entire set of chromatograms, which include two injections for each solution prepared, against the average chromatogram. In the following discussions we will compare chromatograms against the average chromatogram.

An ANOVA study, using OMNITAB [9], was made on the match factors obtained from the chromatograms. It indicated that the match factors for the chromatograms from the same vial were no different than those from different vials on a level of significance with $\alpha=0.05$ [10]. Moreover, the match factors of chromatograms from the two division supply lots and the vials were indistinguishable using the same significance level with $\alpha=0.05$. The samples were run in groups of 10 on different days. Using the match factor we found that chromatograms showed no day-to-day variation.

From this we conclude that there is no statistically significant difference between the contents of vials sampled from the SRMP supply of SRM 2887 and no difference between the SRMP supply and the two division supply lots.

\subsection{Estimation of Impurity Peaks and Polydispersity Index of SRM 2887}

SEC measurements described in the Section 2.3 were used to estimate the polydispersity index (PD). We used the solvents as described in Section 2. Columns for this part of the work were two Waters Styragel HT-6E and one Waters Styragel HT-2 (Waters Corp., Milford, MA) .The 
instrument used for this work was a Waters Alliance GPCV 2000 (Waters Corp., Milford, MA) . Columns were calibrated with SRM 1482, SRM 1483, SRM 1484, SRM 1475, SRM 2885, SRM 2886, and SRM 2887. From the SEC curves for SRM 2887 we estimated the PD (PD $\left.=M_{w} / M_{n}\right)$ to be 1.29. No effects of column broadening were taken into account in this measurement, so we expect the value of 1.3 to be an overestimate of the PD.

In a separate calculation, we tried to take the effects of column broadening into account using the Waters Corporation Millennium Software (Waters Corp., Milford, MA) . Using their Axial Dispersion Calculation with peak compression, we found a PD of 1.23.

SEC analysis of the chromatograms from SRM 2887 showed a minor peak at around $80 \times 10^{+3}$ $\mathrm{g} / \mathrm{mol}$. We assume the minor peak arises from a small quantity of a lower molecular mass fraction that was not removed during fractionation. Analysis of chromatograms from four different vials yielded RI signals for the minor peak ranging from $2.0 \%$ to $3.3 \%$ of the main peak. We take $3.3 \%$ as the upper fractional limit of the RI signal and, therefore, the maximum fractional mass in the minor peak. The $\mathrm{M}_{\mathrm{w}}$ measured by light scattering will, of course, include the low mass fraction.

$$
\mathrm{M}_{\mathrm{w}-\mathrm{LS}}=(1-\mathrm{f}) \mathrm{M}_{\mathrm{w}-\text { main peak }}+\mathrm{f} \mathrm{M}_{\mathrm{w} \text {-minor peak }}
$$

where $\mathrm{M}_{\mathrm{w}-\mathrm{LS}}$ is the mass averaged molecular mass from light scattering, $\mathrm{M}_{\mathrm{w} \text {-main peak }}$ is the mass averaged molecular mass of the main SRM 2887 peak, $\mathbf{M}_{\mathrm{w} \text {-minor peak }}$ is the mass averaged molecular mass of the minor peak, $80 \times 10^{3} \mathrm{~g} / \mathrm{mol}$, and $\mathrm{f}$ is the fraction of signal in the minor peak. We can then estimate the main peak $\mathrm{M}_{\mathrm{w} \text {-main peak }}$ as

$$
\mathrm{M}_{\mathrm{w} \text {-main peak }}=\left(\mathrm{M}_{\mathrm{w}-\mathrm{LS}}-\mathrm{f} \mathrm{M}_{\mathrm{w}-\text { minor peak }}\right) /(1-\mathrm{f})
$$

Using our estimate of $\mathrm{M}_{\mathrm{w} \text {-minor peak }}$ and $\mathrm{f}$ we calculate the value of

$$
\mathrm{M}_{\mathrm{w} \text {-main peak }}=200,400 \mathrm{~g} / \mathrm{mol} \text {. }
$$

The maximum error in taking the measured light scattering mass average molecular mass, $\mathbf{M}_{\mathrm{w}-\mathrm{LS}}$, as the estimation of the $\mathrm{M}_{\mathrm{w} \text {-main peak }}$ is then $4000 \mathrm{~g} / \mathrm{mol}$, much less than our estimated overall uncertainty in the light scattering mass average molecular mass, $\mathrm{M}_{\mathrm{w}-\mathrm{LS}}$.

\subsection{Intrinsic Viscosity of SRM 2887}

4.1 Measurement of the Intrinsic Viscosity

Viscosity measurements were made with a Schott-Gerate Ubbelohde micro-viscometer (SchottGerate GMBH, Hofheim, Germany) with a Schott-Gerate constant temperature bath held at 
$130{ }^{\circ} \mathrm{C}$. Flow times were measured by the Schott-Gerate AVS 400. The solvent, 1,2,4trichlorobenzene (TCB), was obtained from Aldrich Chemical (1,2,4-trichlorobenzene, 99+\%, spectrophotometric grade, Aldrich Chemical, Milwaukee, WI) and used as received. Butylated hydroxytolulene (2,6-Di-tert-butyl-4-methylphenol), also obtained from Aldrich Chemical, was added to the solvent at about $0.7 \mathrm{~g} / \mathrm{L}$ as an antioxidant.

Solution concentrations ranging from $0.2 \mathrm{~g} / \mathrm{L}$ to $1.0 \mathrm{~g} / \mathrm{L}$ were prepared from independent weighing of polymer and solvent, rather than employing successive dilution techniques. Concentrations were calculated from densities and partial specific volumes determined earlier in this laboratory [11].

The polymer was dissolved by heating the mixture to $135{ }^{\circ} \mathrm{C}$ to $140{ }^{\circ} \mathrm{C}$ in a hot air oven with occasional stirring. Solutions were then transferred to a viscometer by filtering the solution though a syringe and syringe filter heated in the same oven. The syringe filter assembly used was a Swinny Stainless $25 \mathrm{~mm}$ (Millipore Corp., Bedford, MA) while the filter membrane was a PallGelman Sciences ZEFLOUR all Teflon $0.5 \mu \mathrm{m}$ pore size $25 \mathrm{~mm}$ diameter membrane (Pall Corp., Port Washington, NY).

For each polymer concentration, flow times were measured for both solvent and solutions. The AVS 400 is designed to perform a number of preconditioning runs to insure that the solution or solvent comes to temperature equilibrium before the actual measurements were made and recorded. The operation of the AVS 400 took about $2 \mathrm{~min}$ to $2.5 \mathrm{~min}$ for each of the five preconditioning runs. Five flow times were measured on each aliquot of the solvent or the solution. Flow times measured in this viscometer ranged from $40 \mathrm{~s}$ to $60 \mathrm{~s}$.

At the beginning of an overall measurement on a solution, the viscometer was flushed with at least three solvent aliquots. Then, at least two aliquots of solvent were introduced for flow time measurements. Three aliquots of solution were used to flush the viscometer. Three aliquots of solution were then measured. Three aliquots of solvent were used to flush the viscometer. Finally, flow time measurements were made on three aliquots of solvent.

\subsection{Results of Solution Viscosity}

The solution viscosity, $\eta(\mathrm{c})$, may be expanded as a power series in solution concentration, $c$, [12]

$$
\eta(c)=\eta(0)\left(1+a_{1} c+a_{2} c^{2}+\ldots\right)
$$

where $\eta(0)$ is the solvent viscosity.

The viscosity number is defined as

$$
(\eta(c)-\eta(0)) /(\eta(0) c)=a_{1}+a_{2} c
$$


The intrinsic viscosity, $[\eta]=a_{1}$, is the zero concentration limit of the viscosity number.

For a properly designed capillary viscometer, the solution viscosity is almost proportional to the product of the solution density and the measured flow time. The deviation from proportionality is due to a combination of kinetic energy effects and hydrodynamic effects at the end of the capillary. The manufacturer of the viscometer gives tables to correct the measured times for each viscometer. These corrections, designated by the manufacturer as the Hagenbach correction [13], are approximately of the form $1 / \mathrm{t}_{\mathrm{m}}{ }^{2}$, where $\mathrm{t}_{\mathrm{m}}$ is the measured time. The manufacturer's corrections were fitted to this form to interpolate their correction data. This correction is applied to each average flow time for solvent or solution yielding $\mathrm{t}(\mathrm{c})$ where the $\mathrm{c}$ refers to the concentration of the solution being measured.

From eq. 2 then

$$
K \rho(c) t(c)=K \rho(0) t(0)\left(1+a_{1} c+a_{2} c^{2} \ldots . .\right)
$$

where the solvent viscosity is

$$
\eta(0)=K \rho(0) t(0)
$$

and $\mathrm{K}$ is the viscometer constant.

Finally, we do not need to know $\mathrm{K}$ since the quantity of interest is the limiting value of

$$
[\eta]=(\eta(c)-\eta(0)) /(\eta(0) c)=a_{1}
$$

Thus we may rewrite eq. 4 as

$$
\rho(c) t(c)=\rho(0) t(0)\left(1+a_{1} c+a_{2} c^{2} \ldots\right)
$$

On any given day measurements on only one concentration and related solvents as described above were practical. As viscometers became dirty, they were taken out of service and similar, but not identical, clean ones used in their place. Thus, the ratio, $\mathrm{T}(\mathrm{c})$, is expected to be invariant at any concentration where $T(c)$ is

$$
\mathrm{T}(\mathrm{c})=(\rho(\mathrm{c}) \mathrm{t}(\mathrm{c})-\rho(0) \mathrm{t}(0)) /(\rho(0) \mathrm{t}(0))
$$

Following the normal definition of $[\eta]$ as the zero concentration limit of $T(c) / c$, we fit $T(c) / c$ to the expression 


$$
\mathrm{T}(\mathrm{c}) / \mathrm{c}=\mathrm{a}_{1}+\mathrm{a}_{2} \mathrm{c} .
$$

The value of $\mathrm{a}_{1}$ so obtained was $276.9 \mathrm{~mL} / \mathrm{g}$ with a standard deviation of $2.5 \mathrm{~mL} / \mathrm{g}$. For our study of uncertainty, we consider the value of the standard deviation reported above to be the expanded uncertainty in the repeatability of the measurement. This is reported in Table 1 with other contributions to the reported uncertainty of this measurement.

The coefficient $\mathrm{a}_{2}$ is related to the Huggins constant [14] as

$$
\mathrm{k}_{\mathrm{H}}=\mathrm{a}_{2} /\left(\mathrm{a}_{1}\right)^{2} \text {. }
$$

We obtain the value of $\mathrm{k}_{\mathrm{H}}$ of $0.45 \mathrm{~g} / \mathrm{mL}$.

Earlier, Wagner and Verdier [12] studied other fractions of the same base material, SRM 1475, certified as SRM 1482, SRM 1483 and SRM 1484. They measured and reported limiting viscosities in TCB on these materials. Fitting their data for the limiting viscosities, [ $\eta$ ], of SRM 1482, SRM 1483 and SRM 1484, we obtain

$$
\ln _{\mathrm{e}}\left\{[\eta]_{\mathrm{w}}\right\}=0.7312 \ln _{\mathrm{e}}\left\{\mathrm{M}_{\mathrm{w}}\right\}-3.247
$$

where $[\eta]_{\mathrm{w}}$ is their measured intrinsic viscosity.

Using the $\mathrm{M}_{\mathrm{w}}$ of our polymer obtained in Section 5, we estimate [ $\left.\eta\right]_{\mathrm{w}}$ from eq. 11 for SRM 2887 to be $289 \mathrm{~mL} / \mathrm{g}$, in good agreement with our measured value considering the fact that the $[\eta]_{\mathrm{w}}$ is an extrapolated value. Furthermore, extrapolating their $\mathrm{k}_{\mathrm{H}}$, we estimate $\mathrm{k}_{\mathrm{H}}$ for this molecular mass as $0.48 \mathrm{~g} / \mathrm{mL}$, again in good agreement with our value.

\subsection{Estimating Uncertainties in the Intrinsic Viscosity Measurement}

The likely sources of uncertainty are discussed in the following subsections and the table referred to herein. For this analysis, we largely follow the paper of Wagner and Verdier [12].

\subsubsection{Shear Rate Dependence of Viscosity}

Low molecular mass polymers in dilute solution are expected to show little, or no shear rate dependence. Wagner and Verdier [2] were unable to detect shear rate dependence, even for SRM 1484 , a linear polyethylene with an $\mathrm{M}_{\mathrm{w}}$ of $114,000 \mathrm{~g} / \mathrm{mol}$. The capillary in their viscometer had a smaller diameter than that in the Schotte-Gerate viscometer used in the present measurements. Thus, we expect little shear rate dependence of the intrinsic viscosity of SRM 2887, even though SRM 2887 is of higher molecular mass than SRM 1484. 
To confirm the above assertion, we estimate the ratio of the intrinsic viscosity at zero shear rate, $[\eta]_{0}$, to the shear rate, $\gamma$, of the viscometer, [ $\left.\eta\right]_{\tilde{a}}$. Booij, Schoffeleers and Haex [15] examined the shear rate dependence of the limiting viscosity of high molecular mass polyethylene with broad polydispersity. They suggested that their viscosity data were best described by an equation that reduces, for polymers of narrow polydisperty and at low shear rates, to

$$
[\eta]_{\mathrm{a}} /[\eta]_{0}=1-\left(\dot{\gamma} \hat{\mathrm{o}}_{\mathrm{m}}\right)^{2}
$$

where

$$
\hat{\mathrm{o}}_{\mathrm{m}}=\left(\mathrm{A}_{0} \eta_{\mathrm{s}}[\eta]_{\mathrm{w}} \mathrm{M}_{\mathrm{w}}^{(1+\mathrm{r})}\right) / \mathrm{RT}
$$

and $[\eta]_{\tilde{a}}$ is the limiting viscosity at shear rate $\gamma,[\eta]_{0}$ is the limiting viscosity at zero shear rate, $\eta_{S}$ is the viscosity of the solvent, $R$ is the Boltzmann constant, $T$ is the temperature, and $A_{0}$ is a constant $\mathrm{O}(1)$. They find the exponent $\mathrm{r}=-0.7$ from their data. We estimate $\gamma \hat{\mathrm{o}}_{\mathrm{m}} \approx 2 \times 10^{-6}$ for shear rates of $2000 \mathrm{~s}^{-1}$ estimated from the manufacturer's specifications for our viscometers. We can make a much more conservative estimate of $\gamma \hat{o}_{m}$ using the characteristic relaxation time estimated from a Rouse Zimm like model, see references in [15]. For the latter model, with $r=0$ and $\mathrm{A}_{0}=1$, we obtain $\gamma \hat{\mathrm{o}}_{\mathrm{m}} \approx 0.016$. This yields a fractional correction of $0.03 \%$ to the limiting viscosity. We thus assume no correction for the shear rate dependence of the limiting viscosity.

\subsubsection{Solution Concentration and Density}

According to Wagner and Verdier [12], their reported value of $\rho(0)$ has an estimated relative expanded uncertainty of $0.2 \%$ and their reported value of the specific volume of the polymer in solution, $\mathrm{v}_{\text {avg }}$, has an expanded uncertainty of $0.04 \mathrm{~mL} / \mathrm{g}$. We used their values $\rho(0)$ and $\mathrm{v}_{\text {avg }}$ in our calculations. The solvent density uncertainty leads to $0.6 \mathrm{~mL} / \mathrm{g}$ expanded uncertainty in intrinsic viscosity and the $\mathrm{v}_{\text {avg }}$ uncertainty Wagner and Verdier report leads to $0.04 \mathrm{~mL} / \mathrm{g}$ expanded uncertainty in intrinsic viscosity (see Section 4.3.3).

Wagner and Verdier [12] estimated a relative standard uncertainty $0.03 \%$ in intrinsic viscosity due to the disregard of the buoyancy correction. Since we corrected for buoyancy, we take this uncertainty to be less than $0.01 \%$, or negligible.

All solutions were prepared so that at least $50 \mathrm{mg}$ SRM 2887 was used. We estimated that the balance used for this measurement had an expanded uncertainty of less than $0.1 \mathrm{mg}$. For those solutions where at least $50 \mathrm{mg}$ was used, we estimate a $0.1 \mathrm{mg}$ expanded uncertainty due to weighing would lead to an expanded uncertainty of $0.5 \mathrm{~mL} / \mathrm{g}$. 
Solvent masses were measured with an expanded uncertainty of $0.01 \mathrm{~g}$. A minimum of $30 \mathrm{~g}$ of solvent was used. This uncertainty had negligible effect on the results and so was taken to be zero.

\subsubsection{Specific Volume of the Polymer}

The intrinsic viscosity, $[\eta]$, is the limit of

$$
[\eta]=L\{(\rho(c) t(c)-\rho(0) t(0)) /(\rho(0) t(0) c)\}
$$

where $L\{\}$ is taken to mean the limit at zero concentration. Following Wagner and Verdier [12] using the fact that the limit of the product is the product of the limit, they find

$$
[\eta]=\rho(0)^{-1}\left(1+2 \mathrm{~K}^{\prime} / \mathrm{t}_{\mathrm{m}}(0)^{+3}\right) /\left(1-\mathrm{K}^{\prime} / \mathrm{t}_{\mathrm{m}}(0)^{+3}\right) * \mathrm{~L}\left\{\left(\mathrm{t}_{\mathrm{m}}(\mathrm{c})-\mathrm{t}_{\mathrm{m}}(0)\right) /\left(\mathrm{t}_{\mathrm{m}}(0) \mathrm{w}\right)\right\}+\rho(0)^{-1}-\mathrm{v}_{\mathrm{avg}}
$$

where $\mathrm{w}$ is the mass fraction of solute in the solution and $\mathrm{K}^{\prime}$ is the kinetic energy term derived from corrections given by the viscometer manufacturer [13].

This formula corrects a typographical error in their formula 11. The formula shows that the intrinsic viscosity as made up of two terms if we disregard the kinetic energy (KE) corrections of the viscometer. Assuming these KE corrections are zero we get then

$$
[\eta]=\tilde{n}(0)^{-1} L\left\{\left(t_{m}(c)-t_{m}(0)\right) /\left(t_{m}(0) w\right)\right\}+\tilde{n}(0)^{-1}-v_{\text {avg }}
$$

The last two terms are the difference between the specific volume of the solvent, $\rho(0)^{-1}$, and the specific volume of the polymer in solution, $v_{\text {avg }}$. This difference is small, about a few tenths of an $\mathrm{mL} / \mathrm{g}$, compared to an overall intrinsic viscosity of $276.9 \mathrm{~mL} / \mathrm{g}$ for this polymer. Since $\mathrm{v}_{\text {avg }}$ was determined on other fractions of this polymer previously $[11,12]$, we estimate that our value of $\mathrm{v}_{\text {avg }}$ has an uncertainty of no more than $0.04 \mathrm{~mL} / \mathrm{g}$. Thus, we take $0.04 \mathrm{~mL} / \mathrm{g}$ to be the uncertainty in intrinsic viscosity from this contribution.

\subsubsection{Timer Uncertainties}

Individual flow times were recorded to $0.01 \mathrm{~s}$. We take this to be the expanded uncertainty of the timer measurements. Since the intrinsic viscosity is the ratio of the time differences over a time, only the uncertainty in the time in the denominator is important. Since total flow times were 
between $40 \mathrm{~s}$ and $60 \mathrm{~s}$, a $0.01 \mathrm{~s}$ timer uncertainty would cause an expanded uncertainty of no more than $0.1 \mathrm{~mL} / \mathrm{g}$.

\subsubsection{Kinetic Energy or Hagenbach Corrections}

As noted above, kinetic energy, or Hagenbach, corrections were estimated from tables given by the viscometer manufacturer [13] and obey a $\mathrm{G} / \mathrm{t}(\mathrm{c})^{2}$ law. The value of $\mathrm{G}$ estimated from the manufacturer's table is $412 \mathrm{~s}^{3}$ for our viscometer. We take our value of $\mathrm{G}$ to have a relative expanded uncertainty of $20 \%$, twice that assumed by Wagner and Verdier [12] for their value of G. This leads to an expanded uncertainty of $0.8 \mathrm{~mL} / \mathrm{g}$ in the intrinsic viscosity of SRM 2887.

We may estimate this correction in a different way. If we do not consider kinetic energy corrections to the measured data, we compute an apparent intrinsic viscosity that differs from the value estimated by $4.8 \mathrm{~mL} / \mathrm{g}$. If we take $20 \%$ of this difference as a measure of the uncertainty, we estimate $1.0 \mathrm{~mL} / \mathrm{g}$ is consistent with the expanded uncertainty estimated above. We take 1.0 $\mathrm{mL} / \mathrm{g}$ as the expanded uncertainty from any error in the kinetic energy correction.

\subsubsection{Uncertainties Arising from Temperature Uncertainties}

Wagner and Verdier [12] estimate the relative temperature dependence of the intrinsic viscosity of polyethylene to be no more than $0.2 \% /{ }^{\circ} \mathrm{C}$ for polyethylene in theta solvents. The temperature dependence is expected to be less in TCB, which is a good solvent for polyethylene. Following Wagner and Verdier, we take $1 \% /{ }^{\circ} \mathrm{C}$ as the outside limit of the temperature dependence of intrinsic viscosity. We believe the Schott-Gerate constant temperature bath controls the temperature much better than $0.3{ }^{\circ} \mathrm{C}$, including effects of temperature gradients. This conclusion arises partly because we have a reproducibility of better than $0.10 \mathrm{~s}$ out of about $41 \mathrm{~s}$ for the solvent flow times taken over a period of weeks. Further, we found a $1{ }^{\circ} \mathrm{C}$ change in temperature altered the measured flow time of the solvent by $0.32 \mathrm{~s}$. Thus, we take $0.8 \mathrm{~mL} / \mathrm{g}$ as the expanded uncertainty from the temperature.

\subsubsection{Estimated Combined Expanded Uncertainty}

In Table 1, the estimated expanded uncertainties from all sources are listed. Following NIST guidelines [16] we obtain the combined expanded uncertainties as the root sum of squares of these quantities.

\subsection{Determination of $M_{w}$ of SRM 2887 by Light Scattering}




\subsection{Solvent Preparation for Light Scattering and for Specific Refractive Index Increment}

The light scattering solvent, 1-chloronaphthalene, was purchased from Aldrich Chemical (Aldrich Chemical, Milwaukee, WI). According to the supplier, this 1-chloronaphthalene was 90 $\%$ pure with 2-chloronaphthalene as the only detectable impurity. A two-step purification method, described in Appendix II of reference [3], involved crystallizing out the 2chloronaphthalene followed by vacuum distillation of the 1-chloronaphthalene.

The antioxidant Santonox, 3-tert-Butyl-4-hydroxy-2-methylphenyl sulfide (Aldrich Chemical, Milwaukee, WI), was added to the purified 1-chloronaphthalene in order to protect the polyethylene from oxidative degradation during the high temperature light scattering experiments and differential refractive index determinations. The antioxidant was dissolved in the 1chloronaphthalene at a concentration of $0.1 \mathrm{~g} / \mathrm{L}$ at $130^{\circ} \mathrm{C}$.

The 1-chloronaphthalene was sparged with dry nitrogen gas for a few hours immediately before adding solvent to polymer samples in preparing solutions to conduct experiments. The nitrogen sparging was used to minimize residual oxygen content in the solvent.

Solvent recovered from light scattering experiments was recycled. After the solutions had been allowed to cool and the polymer had separated out, the recovered material was drained through a filter. The collected solvent was redistilled by the process described in Appendix II of reference [3]. Since the 2-chloronaphthalene impurities had already been removed exhaustively from such recovered solvent earlier, the preparatory refluxing process to remove the isomer was omitted.

\subsection{Determination of Specific Refractive Index Increment}

\subsubsection{Instrumentation}

The specific refractive index increment (dn/dc) for SRM 2887 was determined using a Chromatix KMX-16 (Thermo-Separation Products, Sunnyvale, CA) differential refractometer. The refractometer light source was a helium-neon ( $\mathrm{He}-\mathrm{Ne})$ laser operating at a wavelength of $632.8 \mathrm{~nm}$. For room temperature calibration, the measurement cell was controlled at $25^{\circ} \mathrm{C}$. The measurement cell was heated to $130{ }^{\circ} \mathrm{C}$ for the solution and solvent measurements.

\subsubsection{Calibration of Instrument at Room Temperature}

The differential refractometer was calibrated with aqueous $\mathrm{NaCl}$ solutions at $25^{\circ} \mathrm{C}$. Refractive increments versus concentration for several aqueous electrolyte solutions at several wavelengths of light had been reported by Kruis [17]. Refractive increments for the same solutions at the HeNe laser wavelength, $632.8 \mathrm{~nm}$, have been determined from interpolation of the data in the Kruis 
tables [17,18]. A cubic equation for these refractive increments as a function of $\mathrm{NaCl}$ concentration in aqueous solution at $25^{\circ} \mathrm{C}$ is given in the instrument manual, and was used to compute the refractive increments of the aqueous $\mathrm{NaCl}$ solutions prepared as standards for calibrating the differential refractometer.

Analytical reagent $\mathrm{NaCl}$ (Baker and Adamson, Allied Chemical and Dye Corp, New York, NY) was dried in a hot air oven for approximately $18 \mathrm{~h}$ at a temperature of $140{ }^{\circ} \mathrm{C}$ in preparation to be used as a calibrant. Distilled water was degassed by boiling and left to cool to ambient temperature overnight in storage bottles tightly capped with zero headspace. The storage bottles had been leached out with several changes of boiling distilled water before being used to contain the degassed distilled water. Both salt and water components of each solution were measured gravimetrically, and atmospheric buoyancy corrections were applied to compute the concentrations as $\mathrm{g} \mathrm{NaCl} / 100 \mathrm{~g} \mathrm{H}_{2} \mathrm{O}$.

Following instructions in the instrument instruction manual [19] calibration measurements for the differential refractometer were conducted on four $\mathrm{NaCl}$ solutions ranging in concentration from $0.5 \mathrm{~g} \mathrm{NaCl} / 100 \mathrm{~g} \mathrm{H}_{2} \mathrm{O}$ to $2.0 \mathrm{~g} \mathrm{NaCl} / 100 \mathrm{~g} \mathrm{H}_{2} \mathrm{O}$ in intervals of $0.5 \mathrm{~g} \mathrm{NaCl} / 100 \mathrm{~g} \mathrm{H}_{2} \mathrm{O}$. The

calculated refractive increments of the solutions were fitted to their average image displacements to generate a linear calibration equation of refractive increment versus image displacement, $\mathrm{dn} / \mathrm{dc}$. The instrument calibration was found to be insignificantly changed from calibrations made many years earlier indicating that we were simply verifying an earlier calibration. In fact, the plot of the calibration verification points, when overlaid on an earlier instrument calibration plot, produced a graph in which the two data sets were indistinguishable.

\subsubsection{Solution Preparation and Handling}

Polymer solutions were prepared using 1-chloronaphthalene solvents with a mass fraction $0.01 \%$ Santonox (Aldrich, Milwaukee, WI) antioxidant. The 1-chloronaphthalene (Aldrich, Milwaukee, WI) was purified by distillation before use as described in Appendix II of reference [3]. Solution concentrations in ranges described in Section 5.6.7 were made directly by weighing, without employing successive dilution techniques. Concentrations were calculated from densities and partial specific volumes determined earlier in this laboratory [11]. A general-purpose laboratory convection oven set at a temperature of approximately $145^{\circ} \mathrm{C}$ was used to dissolve the polymer solutions. Glass bottles with ground glass necks and caps were used as dissolution vessels for the polymer samples. Experiments conducted earlier (private communication, R.C. Christensen) demonstrated that solvent loss at $130{ }^{\circ} \mathrm{C}$ through the ground glass joint was negligible.

Transfer of the polymer solutions from the glass dissolution vessels into the refractometer measurement cell was accomplished with a specially constructed glass funnel/valve assembly heated to approximately $145^{\circ} \mathrm{C}$. A $6.8 \mathrm{~cm}$ diameter Pyrex glass powder funnel was modified by having the barrel of a $5 \mathrm{~mL}$ glass luer lock syringe attached to the funnel stem. An on-off valve (Popper \& Sons, Inc., New Hyde Park, NY) was attached to the luer fitting and a shortened 20- 
gage needle attached to the valve. The funnel was placed in a heating mantle (Glas-Col, Terre Haute, IN) and a flexible electric heating tape (Barnstead/Thermolyne, Dubuque, IA) was wrapped around the stem, valve and needle that protruded below the heating mantle. The funnel assembly was supported by a three-jaw clamp attached to the funnel stem and an adjustable height rack and pinion post (Edmund Industrial Optics, Barrington, NJ). The rack and pinion post was lowered to position the needle in the sample cell for filling the cell with polymer solution and raised above the cell to provide access to the cell by suction tubing, which was used to empty the cell. Heating mantle and heat tape temperature were measured with a digital thermocouple thermometer (John Fluke Mfg. Co., Palatine, IL) and adjusted by Variac autotransformers (General Radio Co., Cambridge, MA). Dissolved polymer solutions were removed from the oven and poured from the dissolution bottle into the heated funnel. Using the on-off valve on the funnel stem, the refractometer measurement cell was filled with hot polymer solution. Following the instrument instruction manual [19], the cell was filled and emptied five times before measurements were made on the solution.

\subsubsection{Measurement of $(\mathrm{dn} / \mathrm{dc})$ at $130{ }^{\circ} \mathrm{C}$}

Refractive index increments between solvent and solutions of polyethylene in 1chloronaphthalene were determined on solutions that had been prepared on the morning of the day the measurements were made. Six solutions with concentrations between $2.7 \mathrm{~g} / \mathrm{L}$ to $6.0 \mathrm{~g} / \mathrm{L}$ of SRM 2887 were prepared by the procedure describe in Section 5.2.2. For each solution two repeated image displacement measurements were conducted on these solutions of SRM 2887 following methods as outlined in KMX 16 manual. Solvent-versus-solvent measurements were made before and after each solution-versus-solvent measurement. The incremental image displacement by each solution was obtained by subtracting the mean of the bracketing solvent average image displacements from the average image displacement by the solution. The refractive index increment of each solution was computed by application of the calibration equation to the incremental image displacement of the solution. The specific refractive index increments were obtained by dividing the refractive index by the concentration of the solution. The average value of the specific refractive index increment of the solutions was found to be, $\mathrm{dn} / \mathrm{dc}=-0.1798 \mathrm{~mL} / \mathrm{g}$, for SRM 2887 in 1-chloronaphthalene at $130{ }^{\circ} \mathrm{C}$ with a standard uncertainty in the fit of $0.0029 \mathrm{~mL} / \mathrm{g}$. This issue of uncertainty and fit of this measurement will be discussed in Section 5.10.3.

Previous reports of the differential refractive index at $632.8 \mathrm{~nm}$ for other comparable polyethylenes in 1-chloronaphthalene gave values ranging from $-0.178 \mathrm{~mL} / \mathrm{g}$ to $-0.183 \mathrm{~mL} / \mathrm{g}$ at $135{ }^{\circ} \mathrm{C}$. Our value is well in the range of these reported values [21,22]. However, the value we obtained for SRM 2886 is slightly more negative than this value. Normally, the $\mathrm{dn} / \mathrm{dc}$ for these high molecular mass polyethylenes would be expected to be the same. However, for polyethylene, Wagner and Hoeve [20] report molecular mass dependence of $\mathrm{dn} / \mathrm{dc}$, even at high molecular masses. 


\subsection{Refractive Indices of Solvent and Calibrant}

The primary standard for this measurement is benzene; other standards are derived from it. The refractive index of the benzene primary standard at $23{ }^{\circ} \mathrm{C}$ and $632.8 \mathrm{~nm}$ is taken to be $1.4941[23,24]$.

G. B. Arrowsmith, G. H. Jeffrey, and A. I. Vogel [25] tabulated the refractive index at the Sodium D line $\mathrm{n}_{\mathrm{D}}=1.63315$ at $20{ }^{\circ} \mathrm{C}$ and a density at $20{ }^{\circ} \mathrm{C}$ of $1.1932 \mathrm{~g} / \mathrm{mL}$ for 1 chloronaphthalene. Christensen [11] reported the density of 1-chloronaphthalene as $1.098 \mathrm{~g} / \mathrm{cm}^{3}$ at $130{ }^{\circ} \mathrm{C}$ and Wagner [26] reported the density of 1-chloronaphthalene as 1.098 $\mathrm{g} / \mathrm{cm}^{3}$ at $135^{\circ} \mathrm{C}$. The Lorentz-Lorenz molar refraction relation is used to estimate the refractive index for 1-chloronaphthalene at $130{ }^{\circ} \mathrm{C}$ from the densities at $20{ }^{\circ} \mathrm{C}$ and $130{ }^{\circ} \mathrm{C}$ and the refractive index at $20{ }^{\circ} \mathrm{C}$. Since the refractive index of 1-chloronaphthalene at $130{ }^{\circ} \mathrm{C}, \mathrm{n}_{\mathrm{D}}=1.5772$, is only used in the reflection correction to the $\mathrm{M}_{\mathrm{w}}$ the limited accuracy of this value is acceptable.

Dow Corning 705 silicone oil is used as the vat fluid. The Lorentz-Lorenz molar refraction relation was applied to the refractive index at $632.8 \mathrm{~nm}$ at $25{ }^{\circ} \mathrm{C}$, and the density at various temperatures (Dow technical consultant Gary McIntyre) to estimate the refractive index of the Dow Corning 705 silicone oil at $130{ }^{\circ} \mathrm{C}$ as $\mathrm{n}_{\mathrm{D}}=1.516$. Since the refractive index of Dow Corning 705 silicone oil $130{ }^{\circ} \mathrm{C}$ is only used in the reflection correction to the $\mathrm{M}_{\mathrm{w}}$ the limited accuracy of this value is acceptable.

\subsection{Design of Light Scattering Instrument}

Dr. Charles Han of the NIST Polymers Division designed and constructed the light scattering apparatus. We review here some of the details of the instrument. A Universal circular dividing table (Universal Vise \& Tool Co.), with a center bore design, is used as the goniometer. This goniometer is mounted on a rigid optical table (Newport Research Corporation). A beam of vertically polarized incident light (wavelength $=632.8 \mathrm{~nm}$ ) is provided by a $10 \mathrm{~mW}$ He-Ne laser (Melles-Griot) also mounted.

The goniometric axis is defined by the center of the goniometer and aligned with a tapered center bore in the goniometer. The vat housing, which contains the sample cell, is mounted on an aligning rod with a precision-machined taper to engage the complementary taper of the center bore of the goniometer. The receptacle hole for the sample cell is machined at the cylindrical axis in the top flange plate of the vat housing. By this arrangement, the center axis of the cylindrical cell and the vat housing are held coincident with the goniometric axis. The intensity of light scattered at varied angles from the sample cell is measured by a photomultiplier in the receiving optics mounted on a rigid beam attached to the goniometer.

The vat is thermostatted by a copper cylinder, which is built onto the underside of the vat housing cover plate, and extends down into the vat fluid. The vat temperature is controlled and indicated by a PID temperature controlling system, a copper constant current supplier, a four wire RTD and 
a voltage comparitor. The controlling system receives a voltage imbalance signal from a fourwired platium resistance temperature probe in the thermostatting cylinder and the voltage comparitor, and sends energy to cartridge heaters in the thermostatting cylinder. When working at high temperatures, significant thermal gradients can develop inside the vat between the thermostatting cylinder and the peripheral region of the vat. Such thermal gradients were repressed by applying a flexible heating mantle to the external cylindrical surface of the vat housing, and controlling the mantle temperature at a few degrees Celsius below the experimental temperature. The mantle was specially constructed for this apparatus, and the control provided by HPS Division, MKS Instrument, Inc. (MKS Instrument, Inc, 5330 Sterling Drive, Boulder, CO 80301).

Light scattering cells were fabricated from precision ground and polished glass tubing to uniform wall thickness (Wilmad Glass Co.), with both inside and outside cylindrical surfaces polished. The tubing is of $33 \mathrm{~mm}$ outside diameter and has a refractive index $\mathrm{n}_{\mathrm{D}}=1.50$.

\subsection{Instrument Calibration Protocol at $130{ }^{\circ} \mathrm{C}$}

1,2,4-trichlorobenzene (TCB) (Aldrich Chemical high purity, Milwaukee, WI) was employed as the working light scattering calibration standard at $130{ }^{\circ} \mathrm{C}$. The calibration of TCB as the working standard is traced to the Rayleigh ratio $\left(\mathrm{R}_{\mathrm{V}}\right)$ of benzene at ambient temperature $\left(23{ }^{\circ} \mathrm{C}\right)$ in vertically polarized incident light of $632.8 \mathrm{~nm}$ wavelength, determined by Kaye \& McDaniel [27].

First, a Durasil optical glass rod was calibrated by comparing its scattering intensity at a $90^{\circ}$ angle with that of a benzene cell at the same angle, with the glass rod and benzene cell both at $21{ }^{\circ} \mathrm{C}$. Then the vat temperature was increased to $130{ }^{\circ} \mathrm{C}$ in which environment three TCB cells were calibrated by comparison of their scattering intensities with that of the glass rod. The effective $R_{V}$ of the glass rod is assumed to be invariant with temperature in this range. However, relating the scattering intensity measurements at the two temperatures requires conservation of the optical alignment with change in temperature. The only significant disturbance in the optical alignment results from the change in refractive index of the vat fluid with change in temperature. This problem was solved by conducting the measurements at $21{ }^{\circ} \mathrm{C}$ with the vat filled with anisole which has $n_{D}=1.5160$ at $20{ }^{\circ} \mathrm{C}$, and conducting the measurements at $130{ }^{\circ} \mathrm{C}$ with the vat filled with Dow Corning 705 silicone oil which has $n_{D}=1.516$ at that temperature.

The scattering intensities at $90^{\circ}$ angle $\left(\mathrm{I}_{90}\right)$ of the benzene standard cell and the glass rod standard were measured alternately at $21^{\circ} \mathrm{C}$. A total of 40 such pairs of measurements were conducted over an interval of two days. The resulting population of experimentally determined scattering intensity ratios yielded an average $\left[\mathrm{I}_{90}(\mathrm{GLASS}) / \mathrm{I}_{90}(\mathrm{BENZENE})\right]$ with a relative standard uncertainty of $1.16 \%$.

A series of TCB standard cells was prepared by filtering high purity TCB into each cell through a 
double layer of Millipore cellulose acetate-nitrate membrane with $0.2 \mathrm{ì} \mathrm{m}$ pore size. Filtration of TCB into the cells was conducted at ambient temperature. It was found that a TCB sample could be maintained at the experimental temperature $\left(130{ }^{\circ} \mathrm{C}\right)$ and slightly higher for at least two days without detectable change. A new TCB standard cell was prepared for use with each set of solutions during the characterization of this polymer by light scattering. The $\mathrm{I}_{90}$ of the glass rod standard was compared with the $\mathrm{I}_{90}$ of each of three TCB cells at $130{ }^{\circ} \mathrm{C}$. The $\mathrm{I}_{90}$ values of the glass rod and the TCB cell were measured alternately. A total of 14 pairs of such $\mathrm{I}_{90}$ measurements were conducted with the glass rod and each of the TCB cells, resulting in three average values for the ratio $\left[\mathrm{I}_{90}(\mathrm{TCB}) / \mathrm{I}_{90}(\mathrm{GLASS})\right]$ in very close agreement. The three determinations resulted in a single average value for the ratio with a relative standard uncertainty of $0.20 \%$.

As small error was introduced because we measured the ratio of scattering from benzene to the glass cell, S, at $21{ }^{\mathrm{O}} \mathrm{C}$ not at $23^{\mathrm{O}} \mathrm{C}$ where the $\mathrm{R}_{\mathrm{v}}$ was measured by Kaye and McDaniel [27]. Ehl, Loucheux, Reiss, and Beniot [28] have measured this temperature variation. Our measurements of $\mathrm{S}$ give us $\mathrm{S}_{21}$, the $\mathrm{S}$ at $21{ }^{\mathrm{O}} \mathrm{C}$. We need $\mathrm{S}_{23}$, the ratio measured with benzene and the glass rod at $23{ }^{\mathrm{O}} \mathrm{C}$. From Ehl, Loucheux, Reiss and Beniot [28] we estimate

$$
\mathrm{S}_{23}=0.9946 \mathrm{~S}_{21}
$$

As noted earlier, Kaye and McDaniel [27] determined the value $\mathrm{R}_{\mathrm{V}}=12.6_{3} \times 10^{-6}$ for benzene under these optical conditions, with a standard uncertainty of $0.21 \times 10^{-6}$. The product of ratios, $\left[\mathrm{I}_{90}(\mathrm{GLASS}) / \mathrm{I}_{90}(\mathrm{BENZENE})\right]$ and $\left[\mathrm{I}_{90}(\mathrm{TCB}) / \mathrm{I}_{90}(\mathrm{GLASS})\right]$ gave a value of $\mathrm{S}_{21}$. This was applied to the $\mathrm{R}_{\mathrm{V}}$ for benzene by Kaye and McDaniel to estimated working value of $\mathrm{R}_{\mathrm{V}}=35.6 \times 10^{-6}$ for the TCB at $130^{\circ} \mathrm{C}$ in vertically polarized incident light of $632.8 \mathrm{~nm}$ wavelength. The standard uncertainty for this value of $S_{21}$ is computed as the root sum of squares of the standard uncertainties of the two ratios.

This method of calibration was tested by using TCB as the working standard in light scattering experiments to determine the molecular mass $\left(\mathrm{M}_{\mathrm{w}}\right)$ of the polyethylene standard, SRM 1483 . The resulting $\mathrm{M}_{\mathrm{w}}$ from these experiments conducted with TCB as the calibrating standard were statistically indistinguishable from the certificate value of the $\mathrm{M}_{\mathrm{w}}$ for SRM 1483 [2].

\subsection{Solution Preparation}

SRM 2887 samples from the SRMP vials were weighed on an OHAUS GA200D analytical electrobalance (Ohaus Corp., Florham Park, NJ), with $0.0001 \mathrm{~g}$ resolution, and transferred to sample bottles. All polymer samples weighed $30 \mathrm{mg}$ or greater in order to repress relative uncertainty in the sample mass. The 1-chloronaphthalene was sparged for $2 \mathrm{~h}$ with dry $\mathrm{N}_{2}$ gas. The sparged solvent was then measured into bottles containing the polymer samples, plus two empty bottles to contain solvent samples. The solvent mass was determined by mass difference on a Mettler PE 3600 electrobalance.(Mettler Toledo, Columbus,OH). Atmospheric buoyancy 
corrections and densities of solvent and polymer were applied to calculate absolute solution concentrations at the experimental temperature. Both balances were checked during the certification period often by a NIST calibrated $50 \mathrm{mg}$ mass for the Ohaus balance and a NIST calibrated $50 \mathrm{~g}$ mass for the Mettler. The balances read with accuracy to the last reading value.

Solution concentrations in range described in Section 5.9 were made directly by weighing, without employing successive dilution techniques. Concentrations were calculated from densities and partial specific volumes determined earlier in this laboratory [11]. The bottles were capped with ground glass tops and placed in an oven at about $150{ }^{\circ} \mathrm{C}$. They were heated and agitated occasionally for about $2 \mathrm{~h}$ before commencing filtration.

The syringe filter assembly used was a $25 \mathrm{~mm}$ diameter stainless steel Swinny type (Millipore Corp., Bedford, MA). The Swinny filter was attached to a glass syringe modified by adding a spherical joint at the top end, to provide connection to a dry nitrogen source used to apply an inert low-pressure gas to propel solution through the filter at a realistic rate. Each Swinny was assembled with a double layer of Pall-Gelman Sciences ZEFLUOR all-Teflon filtering membrane with 0.5 ì m pore size (Pall Corp., Port Washington, NY). These filtering assemblies were heated to $150{ }^{\circ} \mathrm{C}$ in the oven along with the solvent and solution bottles.

After the polymer samples had dissolved to form clear homogeneous solutions, the solvent and solution samples were filtered into their respective light scattering cells.

The hot filtration was conducted in a thermostatted apparatus that maintained both cell and filtering assembly in the range $140{ }^{\circ} \mathrm{C}$ to $150{ }^{\circ} \mathrm{C}$. The filtering assembly was heated in a vertical glass cylinder wrapped with a nichrome coil heating element. The cell was mounted in an aluminum block heater below.

After the solution sample was poured into the filtering assembly, and the low nitrogen gas pressure was applied, the first ( 5 to10) $\mathrm{cm}^{3}$ filtrate was collected in a waste vial and discarded. The next approximately $20 \mathrm{~cm}^{3}$ filtrate was directed into the light scattering cell. The $\mathrm{N}_{2}$ gas pressure was adjusted to obtain a filtration flux of about 1 drop per few seconds to a few drops per second.

Subsequent light scattering measurements generally indicated a high success rate in obtaining solution and solvent samples free from dust contamination. At the conclusion of an experiment, the cell components and filtering assembly components were cleaned with refluxing hot xylene vapors. This cleaning process appeared successful in removing dust and polymer exhaustively.

\subsection{Measurement Protocol}

The temperature was controlled at $130.0{ }^{\circ} \mathrm{C} \pm 0.2{ }^{\circ} \mathrm{C}$ in all light scattering measurements on polyethylene in 1-chloronaphthalene. In all experiments, the intensity measuring system was calibrated with the scattering intensity at $90^{\circ}$ angle (I(90)) by a TCB standard cell described 
above; the scattering intensity from the solvent and each solution was measured at eight angles in the range from $45^{\circ}$ to $135^{\circ}$. Scattering intensity measurements versus angle (I(è)) were conducted with the solvent cell immediately following the calibration against TCB, and twice more after I(è) measurements had been conducted on all the solution cells.

All cells containing the TCB secondary standard and samples of solvent or solution were stored in an oven at (140 to150) ${ }^{\circ} \mathrm{C}$. Each cell was transferred from the oven to the vat in preparation for scattering intensity measurements, and allowed to remain undisturbed in the vat for at least $10 \mathrm{~min}$ to equilibrate at the experimental temperature before initiating the measurements.

At the conclusion of each experiment, the TCB secondary standard cell was withdrawn from the oven and stored at ambient temperature. In two cases replicate light scattering experiments were conducted with a set of solution and solvent samples on the day following the initial experiment, after the polyethylene had been in hot solution environment for longer than $24 \mathrm{~h}$. The TCB secondary standard cell was returned to the oven a few hours before initiating the replicate experiment in order to heat it up to the range of experimental temperature. These replicate experiments gave results, which appeared to indicate thermal stability of this polymer in its high temperature solution state over an interval of at least $24 \mathrm{~h}$.

\subsection{Analysis of Light Scattering Data}

Light scattering data from polymer solutions of concentration c and scattering angle $\Theta$ may be analyzed by fitting the scattering signal $\mathrm{I}(\Theta, c)$ to [29]

$$
\mathrm{I}(\Theta, c)=\mathrm{I}(\Theta, 0)+\mathrm{c} \mathrm{I}_{\mathrm{G}} /\left\{(\sin \Theta) \sum_{\mathrm{ij}} \mathrm{C}_{\mathrm{ij}} \mathrm{c}^{\mathrm{i}} \sin ^{2 \mathrm{j}}(\Theta / 2)\right\}
$$

In eq. (17), $\mathrm{I}_{\mathrm{G}}$ is the scattering signal from the TCB working standard at $\Theta=90^{\circ}$.

We must first decide how many terms on the right-hand side of eq. (17) need to be included to provide an adequate fit to the experimental data. The dependence of $c / I_{c}$, where $I_{c}=\sin \Theta[I(\Theta, c)$ $\mathrm{I}(\Theta, 0)] / \mathrm{I}_{\mathrm{G}}$, upon $\mathrm{c}$ and upon $\sin ^{2}(\Theta / 2)$ reflects solute-solvent interactions and solute size, respectively. Accordingly, preliminary scattering data for SRM 2887 were first analyzed as $c / I_{c}$ versus $\sin ^{2}(\Theta / 2)$ and $c$ and $c^{2}$, to see whether a linear expansion (i.e., retaining only $C_{00}, C_{01}$, and $\mathrm{C}_{10}$ ) would provide an adequate fit. The analysis revealed that the linear approximation was adequate at concentrations below $5 \mathrm{~g} / \mathrm{L}$ for SRM 2887 (see Section 5.10.13 for a more complete discussion).

Thus, we used for the final analysis

$$
\mathrm{I}(\Theta, \mathrm{c})=\mathrm{I}(\Theta, 0)+\mathrm{c} \mathrm{I}_{\mathrm{G}} /\left\{\sin \Theta\left(\mathrm{C}_{00}+\mathrm{C}_{01} \sin ^{2}(\Theta / 2)+\mathrm{C}_{10} \mathrm{c}+\mathrm{C}_{20} \mathrm{c}^{2}\right)\right\}
$$

The coefficients in eq. (18) are related to the $\mathrm{M}_{\mathrm{w}}$, molecular mean-square radius of gyration, $\mathrm{R}_{\mathrm{G}}{ }^{2}$, 
the second viral coefficients, $A_{2}$, and the third virial coefficients, $A_{3}$, by $[29,30]$ :

$$
\begin{aligned}
& \mathrm{M}_{\mathrm{w}}=\left(\mathrm{K}^{\prime \prime} \mathrm{C}_{00}\right)^{-1} \\
& \mathrm{R}_{\mathrm{G}}{ }^{2}=3\left[\lambda_{0} /(4 \pi \mathrm{n})\right]^{2} \mathrm{C}_{01} / \mathrm{C}_{00} \\
& \mathrm{~A}_{2}=\mathrm{K}^{\prime \prime} \mathrm{C}_{10} / 2 \\
& \mathrm{~A}_{3}=\mathrm{K}^{\prime \prime} \mathrm{C}_{20} / 3 \\
& \mathrm{~K}^{\prime \prime}=4 \pi^{2} \mathrm{n}_{\mathrm{B}}{ }^{2}(\mathrm{dn} / \mathrm{dc})^{2} /\left(\lambda_{0}{ }^{4} \mathrm{~N}_{\mathrm{A}} \mathrm{R}_{\mathrm{v}}{ }^{\mathrm{B}} \mathrm{S}_{23}\right)
\end{aligned}
$$

where:

$\lambda_{0}$ is the wavelength in vacuum of the scattered light, $632.8 \mathrm{~nm}$ in this work, $\mathrm{n}$ and $\mathrm{n}_{\mathrm{B}}$ are the indices of refraction of the solvent at $130{ }^{\circ} \mathrm{C}$ and benzene at $23{ }^{\circ} \mathrm{C}$ taken as 1.5772 and 1.4941 , respectively calculated as described in Section 5.3, dn/dc is the specific refractive index increment of the solution, measured as described in 5.6.7, $\mathrm{N}_{\mathrm{A}}$ is Avogadro's number, taken as $6.022 \times 10^{23} / \mathrm{mol}, \mathrm{R}_{\mathrm{V}}{ }^{\mathrm{B}}$ is the Rayleigh ratio for the total scattering of vertically polarized light from benzene at $23{ }^{\circ} \mathrm{C}$, used as the calibration standard. $\mathrm{S}_{23}$ is the ratio of the scattering of the benzene at $23{ }^{\circ} \mathrm{C}$ to the TCB working standard at $130{ }^{\circ} \mathrm{C}$. The method of obtaining $\mathrm{S}_{23}$ is described in Section 5.5.

Preliminary fitting was done in the Zimm form, that is, plots of $c / I_{c}$ versus $\sin ^{2}(\Theta / 2)$ and $c$, or if we wish to include third virial terms as $c / I_{c}$ versus $\sin ^{2}(\Theta / 2)$ and $c$ and $c^{2}$. In the Zimm form we found less than $1 \%$ relative change in the fitting parameters, particularly the molecular masses, between the fits including or excluding the $\mathrm{c}^{2}$ term. We then fit to the nonlinear form in eq 18 . This allows us to include the correct weighting of the data and also the zero concentration terms. Again we found only small changes in all fitting parameters between the fit to the Zimm form and the fit to the form of eq. 18 even when we included $c^{2}$ terms in the form of eq. 18 .

\subsection{Results for SRM 2887}

Five sets of light scattering solutions were made from SRM 2887 using 1-chloronaphthalene as solvent. Each set consisted of four to five independently prepared solutions of the approximate concentrations in the range of $(0.3$ to 2$) \mathrm{g} / \mathrm{L}$. The polymer for each solution within each set was taken from the SRM sample vials or the division supply lots. Intensities were measured at eight scattering angles in the range from $45^{\circ}$ to $135^{\circ}$. The intensities of scattered light in each set were fitted by least squares as explained above, and the results were used to calculate $\mathrm{M}_{\mathrm{w}}, \mathrm{A}_{2}, \mathrm{~A}_{3}$, and $R_{g}$ using eqns (19)-(23). The values of $M_{w}, A_{2}, A_{3}$, and $R_{g}$ obtained from the five sets were then averaged. Light scattering gave a $\mathrm{M}_{\mathrm{w}}$ of about $196.4 \times 10^{+3} \mathrm{~g} / \mathrm{mole}$ with a sample standard deviation of $6.6 \times 10^{+3} \mathrm{~g} / \mathrm{mole}$ and a deviation of the mean of $3.0 \times 10^{+3} \mathrm{~g} / \mathrm{mole}$, a value of $\mathrm{A}_{2}$ of $0.00076 \mathrm{~mol} \mathrm{~mL} / \mathrm{g}^{2}$ with a standard deviation of the mean of $0.00009 \mathrm{~mol} \mathrm{~mL} / \mathrm{g}^{2}$, a value of $\mathrm{A}_{3}$ 
of $0.020 \mathrm{~mol} \mathrm{~mL} / \mathrm{g}^{2}$ with a deviation of the mean of $0.010 \mathrm{~mol} \mathrm{~mL} / \mathrm{g}^{2}$ and a value of $\mathrm{R}_{\mathrm{g}}$ of 31.8 $\mathrm{nm}$ with a standard deviation of the mean of $4.1 \mathrm{~nm}$.

Han, Wagner and Verdier [29] in their earlier study on SRM 1482, SRM 1483 and SRM 1484 estimated $R_{g}=8.2 \mathrm{~nm}$ for SRM 1483 which has an $M_{w}=32.1 \times 10^{+3} \mathrm{~g} / \mathrm{mole}$ and $R_{g}=21.7 \mathrm{~nm}$ for SRM 1484 with $M_{w}=119.6 \times 10^{+3} \mathrm{~g} /$ mole. For SRM 1483, they consider the possibilities of large systematic uncertainties in $\mathrm{R}_{\mathrm{g}}$. We have the same problems with the $\mathrm{R}_{\mathrm{g}}$ we estimate. This is due to problem of alignment we find with our I $\sin (\grave{\mathrm{E}})$. Considering all these problems, our value of $31.8 \mathrm{~nm}$ is in close agreement to their values if we do an extrapolation of their data as a function of molecular mass.

The standard deviation of the mean for the average $M_{w}$ of SRM 2887 is $3.3 \times 10^{+3} \mathrm{~g} / \mathrm{mol}$. In compliance with the NIST policy [16] on reporting uncertainties in measurement, the component uncertainty due to variance among the five $\mathbf{M}_{\mathrm{w}}$ determinations is computed as the standard deviation of the mean. Table 3 reports twice this value as the expanded uncertainty.

\subsection{Estimation of Uncertainties Due to Systematic Effects in the Light Scattering}

We list the likeliest sources of systematic uncertainty in the determination of $\mathrm{M}_{\mathrm{w}}$ by light scattering measurements described in the preceding sections, and attempt to estimate upper limits for their magnitudes. For this purpose, we employ a scheme similar to that used in ref. [29] for the estimation of systematic uncertainties in SRM's 1482, 1483 and 1484 and ref [31] on the recertification of SRM 706a. These uncertainties are listed in Table 2 for SRM 2887.

\subsubsection{Indices of Refraction}

Following Ref. [29], we estimate that $0.1 \%$ is a proper upper limit for systematic relative standard uncertainties in $\mathrm{M}_{\mathrm{w}}$ arising from uncertainties in the literature values of benzene index of refraction, the calibrating liquid.

\subsubsection{Calibration of the Differential Refractometer}

\subsubsection{Literature Values of $\mathrm{dn} / \mathrm{dc}$ for Aqueous $\mathrm{NaCl}$}

Calibration of the differential refractometer required interpolation of the data of Ref. [17,18,19] to the $632.8 \mathrm{~nm}$ wavelength used in the light-scattering measurements. We estimate the relative uncertainty in the interpolated values of $\ddot{A}$ as $0.6 \%$, due primarily to uncertainties in the interpolation process. The calibration factor determined for our differential refractometer had a relative standard deviation ( $\mathrm{rsd}$ ) of $0.097 \%$. Applying a coverage factor of 2 to this rsd yields a Type A expanded uncertainty of $0.19 \%$ for this measurand [16]. Combining this uncertainty with an allowance for possible linear uncertainties in the refractometer, we estimate that a proper 
upper limit for relative uncertainty in $\mathrm{dn} / \mathrm{dc}$ is $1 \%$. Considered as a 95 percent confidence interval estimate, this quoted uncertainty provides a expanded uncertainty in $\mathrm{dn} / \mathrm{dc}$ of $1 \%$ which would contribute a $2 \%$ or $4.0 \times 10^{+3} \mathrm{~g} / \mathrm{mol}$ expanded uncertainty in $\mathrm{M}_{\mathrm{w}}$ determination.

\subsubsection{Measured Value of dn/dc of SRM 2887}

The differential refractive index dn/dc of SRM 2887 in 1-chloronaphalene at a temperature of $130{ }^{\circ} \mathrm{C}$ was determined as described in Section 5.2.4. The mean value obtained for $\mathrm{dn} / \mathrm{dc}$ was $-0.1798 \mathrm{~mL} / \mathrm{g}$, with a standard deviation of $0.0029 \mathrm{~mL} / \mathrm{g}$. The uncertainty in the mean is then $0.0013 \mathrm{~mL} / \mathrm{g}$. We take the expanded uncertainty of this measurement as $0.0026 \mathrm{~mL} / \mathrm{g}$ or a relative uncertainty of $1.4 \%$.

There appears to be a small concentration drift in the data. This is mainly due to the highest concentration point. To check the effect of this drift, we refit the data dropping the highest concentration and found a dn/dc of $-0.1791 \mathrm{~mL} / \mathrm{g}$, a number well within our expected expanded uncertainty. Furthermore, an ANOVA of the data did not indicate the that the highest concentration $\mathrm{dn} / \mathrm{dc}$ to fall out of the error expected from the rest of the data. We therefore accept that we can average the data.

As the $\mathrm{dn} / \mathrm{dc}$ appears as the second power in the $\mathrm{M}_{\mathrm{w}}$ calculation, the uncertainty in the calculated $\mathrm{M}_{\mathrm{w}}$ that results from the uncertainty in the $\mathrm{dn} / \mathrm{dc}$ is estimated as twice the estimated relative expanded uncertainty in the $\mathrm{dn} / \mathrm{dc}$, or $2.8 \%$. This gives an expanded uncertainty in the $\mathrm{M}_{\mathrm{w}}$ of 5.6 x $10^{+3} \mathrm{~g} / \mathrm{mole}$.

Contributions to the uncertainty of the value of the density of the solvent to $\mathrm{dn} / \mathrm{dc}$ are discussed in Section 5.10.8.

\subsubsection{Wavelength of Radiation}

For the He-Ne laser employed in this work, uncertainties in the wavelength of the radiation are completely negligible compared with uncertainties from other sources.

\subsubsection{Calibration Constant for Light Scattering}

The protocol for the calibration is described earlier. For each step, we estimate an uncertainty.

\subsubsection{Rayleigh Ratio of Benzene at Room Temperature}

For benzene at $632.8 \mathrm{~nm}$, Ref. [25] gives: $\mathrm{R}_{\mathrm{V}, \mathrm{V}+\mathrm{H}}=12.6_{3} \times 10^{-6} \mathrm{~cm}^{-1}$. We abbreviate $\mathrm{R}_{\mathrm{V}, \mathrm{V}+\mathrm{H}}$ by R. The authors of Ref. [25] apparently believed that their R-values have a relative standard uncertainty of $<2 \%$ (all from systematic uncertainty). They quote a relative standard deviation 
for their R-value for benzene of $0.21 / 12.63$, or $1.7 \%$. This yields a relative expanded uncertainty of $3.9 \%$, or $7.8 \times 10^{+3} \mathrm{~g} / \mathrm{mol}$.

\subsubsection{Estimating Ratio of Benzene Scattering to Glass Rod Scattering at Room Temperature}

We have run 20 repeats of the measurements of the ratio of the scattering of the benzene calibrant to the scattering of the glass rod as described in Section 5.5. We take the uncertainty in the repeatability of this experiment as the overall uncertainty of the measurement. The relative standard deviation of this measurement is given as $1.2 \%$. The relative standard deviation of the mean is $0.27 \%$. We take $0.6 \%$, or $1.2 \times 10^{+3} \mathrm{~g} / \mathrm{mol}$, as the expanded uncertainty from the ratio of the benzene scattering to the glass rod scattering.

A small correction is introduced arising from the fact we calibrated our rod against benzene at $21{ }^{\circ} \mathrm{C}$, rather than benzene at $23{ }^{\circ} \mathrm{C}$. We estimated that correction was 0.9946 from literature value on the temperature variation of the scattering from benzene [28]. We estimate from that work as a generous estimate of the relative expanded uncertainty from this calculation to be $0.2 \%$, or less than $0.4 \times 10^{+3} \mathrm{~g} / \mathrm{mol}$.

From both above corrections we take an expanded uncertainty from all these contributions to be $1.3 \times 10^{+3} \mathrm{~g} / \mathrm{mol}$.

\subsubsection{Temperature Dependence of Scattering of Glass Rod from $21{ }^{\circ} \mathrm{C}$ to $130{ }^{\circ} \mathrm{C}$}

Han, Wagner and Verdier [29] discussed this issue in Section 4.1.3 of their paper on $M_{w}$ determinations of SRM 1482, SRM 1483, and SRM 1484. Since the uncertainty is in the calibration it appears as a percentage of the final result. In that paper, they concluded the maximum relative expanded uncertainty of assuming the scattering of the rod is unchanged from $23{ }^{\circ} \mathrm{C}$ to $130{ }^{\circ} \mathrm{C}$ is $0.4 \%$ of the $\mathrm{M}_{\mathrm{w}}$. Here, we accept their estimate as the expanded uncertainty. This leads to an expanded uncertainty of $\mathrm{M}_{\mathrm{w}}$ for this polymer of $0.8 \times 10^{+3} \mathrm{~g} / \mathrm{mol}$.

\subsubsection{Estimating ratio of Glass Rod Scattering to TCB Scattering at $130{ }^{\circ} \mathrm{C}$}

We have 42 repeat measurements of the ratio of the scattering of the glass rod to the scattering from the TCB working standard, described in Section 5.5. We take the uncertainty in the repeatability of this experiment as the overall uncertainty in this measurement. Fourteen measurements of the ratio of the glass rod scattering to that of TCB, the working standard, were made for each of three different scattering cells containing TCB. The relative standard deviation of the mean is $0.2 \%$. We take 2 times this uncertainty as the expanded uncertainty from the ratio of the benzene scattering to the glass rod scattering. This yields $0.4 \%$ as the relative expanded uncertainty, or $0.8 \times 10^{+3} \mathrm{~g} / \mathrm{mol}$. 


\subsubsection{Uncertainties in the Polarization of Light}

There are two uncertainties associated with the laser light. First, the "vertically polarized" laser beam actually contains "horizontally polarized" components for two reasons: the polarizer inside the laser head lets through a small fraction $\varepsilon$ of the "wrong" polarization and the principal axis of polarization of the light from the laser may not be exactly perpendicular to the optic plane defined by the incident and scattered beams. Both uncertainties will cause light, assumed to be vertically polarized, to contain a small admixture of horizontally polarized light. The effect upon scattering signals from SRM 2887 will be slight, but the effect upon the benzene calibration signals is to change the effective Rayleigh ratio that should have been used toward the $\mathrm{R}_{\mathrm{H}, \mathrm{V}+\mathrm{H}}$ value. The resulting uncertainty in $M_{w}$ is $\varepsilon /(1-\varepsilon)$ for the first effect and $\tan ^{2} \alpha$, where $\alpha$ is the angular mis-setting, for the second. We take $\varepsilon=1 / 500$ and $\alpha=5^{\circ}$. Then the relative expanded uncertainty from $\varepsilon$ is less than $0.2 \%$ with at least a $95 \%$ level of confidence considering the liberal boundaries assigned to the constituent uncertainties. The uncertainty from $\alpha$ is less than $0.8 \%$ with at least a $95 \%$ level of confidence considering the liberal boundaries assigned to the constituent uncertainties. Following NIST guidelines we take the root-sum-of-squares from these contributions to yield the standard uncertainty of $0.85 \%$ and the relative expanded uncertainty from this contribution of $1.7 \%$, or $3.4 \times 10^{+3} \mathrm{~g} / \mathrm{mol}$.

\subsubsection{Ratio of Working Standard Scattering to Sample Scattering}

Since photon-counting techniques were employed, there should be no systematic uncertainties from this source. Random uncertainties are reflected in the overall random uncertainty of the $\mathrm{M}_{\mathrm{w}}$.

\subsubsection{Solvent Density}

For the density of 1-chloronaphalene at $130^{\circ} \mathrm{C}$, we used the value $1.098 \mathrm{~g} / \mathrm{mL}$ as given in references [11,26]. Following Han, Wagner and Verdier [29], we estimate that this value has a relative expanded uncertainty $<0.1 \%$. The resulting relative expanded uncertainty on $\mathrm{M}_{\mathrm{w}}$ is just $0.2 \%$, or $0.4 \times 10^{+3} \mathrm{~g} / \mathrm{mol}$.

\subsubsection{Solute and Solvent Masses}

For the measurements actually used in the final determination of $\mathrm{M}_{\mathrm{w}}$ for SRM 2887, the concentrations employed were nominal (.5 to 2.0$) \mathrm{g} / \mathrm{L}$. Solvent masses were chosen so that the solute masses were always about $0.05 \mathrm{~g}$. Using the uncertainty limit of $0.05 \mathrm{mg}$ we usually assign to the balance used to weigh the PE samples, we have relative uncertainties of $0.1 \%$ in the solute masses. The balance used for solute measurements was regularly checked with a $50 \mathrm{mg}$ mass standard calibrated by the NIST Mass Division and was found to vary by less than $0.01 \mathrm{mg}$ from the standard. The uncertainty in $\mathrm{M}_{\mathrm{w}}$ is then the relative uncertainty in solute masses, or 
about $0.1 \%$ with at least a $95 \%$ level of confidence. This $95 \%$ confidence interval estimate provides a relative expanded uncertainty of $0.2 \%$, or $0.4 \times 10^{+3} \mathrm{~g} / \mathrm{mol}$.

Solvent masses of at least $30 \mathrm{~g}$ were used in solution preparation. The solvent balance was checked against a $100 \mathrm{~g}$ mass standard and found to be off by less than $0.01 \mathrm{~g}$. The solvent masses were measured to $0.01 \mathrm{~g}$. Thus, there are negligible uncertainties in solvent masses.

\subsubsection{Reflection Correction}

The refractive index of 1-chloronaphalene at $130{ }^{\circ} \mathrm{C}$ is given as $\mathrm{n}_{\mathrm{D}}=1.5772$ by an estimate described in Section 5.3. The refractive index of the sample cell is given by the vendor as $\mathrm{n}_{\mathrm{D}}=$ 1.500. Although the wavelength of the reported refractive index of 1-chloronaphalene and of the cell are different from that used in our experiments, these values should be adequate to estimate what will turn out to be an extremely small uncertainty. Han, Wagner and Verdier [29] assumed that the refractive index difference between the sample cell and 1-chloronaphalene was about 0.1 , an extreme overestimation for our case. With that assumption, they found for a scattering system like ours, a reflection correction of 0.1 yields a reflectance factor $\mathrm{f}=2 \times 10^{-3}$. Comparison calculations of $\mathrm{M}_{\mathrm{w}}$ for SRM 1484 with and without this correction show the resulting relative standard uncertainty to be less than $0.01 \%$. The equivalent calculation for SRM 2887 would yield a standard uncertainty of less than $0.01 \%$. We take the uncertainty in the molecular mass from this contribution to be zero.

\subsubsection{Instrumental Misalignment}

The effects of instrument misalignment are difficult to estimate. For the geometry of the current high temperature light scattering instrument, it is expected that any deviation from constancy of I $\sin (\Theta)$ is indicative of instrument misalignment. We look at this effect in two different ways.

First, I $\sin (\Theta)$ values calculated from solvent scattering indicated alignment problems. Whereas these values divided by the intensity at $90^{\circ}$ should be independent of $\Theta$ they showed a fractional variation of $0.6 \%$ to $1.0 \%$. If we assume that the data scales with this uncertainty, we would estimate a relative expanded uncertainty of $0.6 \%$ to $1.0 \%$ in $\mathrm{M}_{\mathrm{w}}$.

Second, from our experience with the alignment, we would also estimate the maximum misalignment to be $0.2^{\circ}$. We have examined two sets of data by purposefully recomputing the $\mathrm{M}_{\mathrm{w}}$ putting in a misalignment of $0.2^{\circ}$. They consistently both show for a systematic angle variation of $+0.2^{\circ}$ the $\mathrm{M}_{\mathrm{w}}$ varies by a fraction of about $1.0 \%$ and for an angle of $-0.2^{\circ}$ the $\mathrm{M}_{\mathrm{w}}$ varies by $-1.0 \%$.

Since both estimates of uncertainty yield a maximum expanded uncertainty of about $1 \%$ from misalignment, we estimate a total relative expanded uncertainty arising from instrument misalignment of $1.0 \%$, or $2.0 \times 10^{+3} \mathrm{~g} / \mathrm{mol}$ for SRM 2887 . 


\subsubsection{Anisotropy of Solute}

Following Han, Wagner, and Verdier [29], we find that equations for $\mathrm{M}_{\mathrm{w}}$ and $\mathrm{K}^{\prime \prime}$ in Section 5.8 are derived on the assumption that the light scattering from the polyethylene is not depolarized. When the solute is optically anisotropy, $\mathrm{M}_{\mathrm{w}}$ should be replaced with $\mathrm{M}_{\mathrm{w}}(1+\varepsilon)$ where the correction term is given by:

$$
\varepsilon=(1 / 45)\left(1 / \mathrm{M}_{\mathrm{w}}\right)\left(\left\langle\gamma^{2}\right\rangle / \mathrm{M}_{\mathrm{w}}\right)\left[4 \pi \mathrm{n}_{\mathrm{s}} \mathrm{N}_{\mathrm{a}} /(\mathrm{dn} / \mathrm{dc})^{2}\right.
$$

where $\left\langle\gamma^{2}\right\rangle$ is given approximately by $267 \times 10^{-50} \mathrm{~cm}^{6}$ per $\mathrm{CH}_{2}$ group [32,33]. Thus $\left\langle\gamma^{2}\right\rangle / \mathrm{M}$ is $1.91 \times 10^{-49} \mathrm{~mL}^{2} / \mathrm{g}$. We estimate $\varepsilon$ for SRM 2887 as 0.0003 . We take this to be a relative expanded uncertainly of $0.03 \%$ on $\mathrm{M}_{\mathrm{w}}$. We consider this correction and uncertainty on this measurement negligible.

\subsubsection{Cutoff of Virial Expansion for SRM 2887}

We follow the method of Han, Verdier and Wagner to judge if our analysis of the data for SRM 2887 is affected by the cutoff of the virial series at the third virial term. First, we notice the third virial has a very large error suggesting the effect of this contribution is small. The error between sets is large and an inspection of our fitting data suggests the error of fit within a set is large too. If we look at the contribution from each term in the series for the average of the sets we find the ratio of terms $\mathrm{C}_{00}: \mathrm{C}_{10} \mathrm{c}: \mathrm{C}_{20} \mathrm{c}^{2}$ at the maximum concentration used for the fitting, $2 \mathrm{~g} / \mathrm{L}$, is 1:0.6: 0.05 which seems to be a rapidly converging series. To check this, we examined the effect of the fourth virial on the calculated quantities. Following Han, Verdier and Wagner, we estimate $\mathrm{C}_{30} \leq \mathrm{C}_{10} \mathrm{C}_{20} / \mathrm{C}_{00}$. The equality gives the maximum contribution from $\mathrm{C}_{30}$. The effect of the maximum size of the $\mathrm{C}_{30}$ contribution was estimated by subtracting the value of $\mathrm{C}_{30} \mathrm{c}^{3}$ from every data point. The $\mathrm{M}_{\mathrm{w}}$ was recomputed from these modified data. The change in molecular mass from the data without the contribution was used to estimate the maximum relative standard uncertainty resulting from this contribution. For the five data sets the effect ranged from $0.15 \%$ to $0.25 \%$. We estimate the relative expanded uncertainty from this contribution to be $0.5 \%$, or $1.0 \times 10^{3} \mathrm{~g} / \mathrm{mol}$.

\subsubsection{Scattering Changing during the Measurement: Degradation and other Sources}

By their nature light scattering experiments are of short duration. A number of solutions can be prepared and examined by light scattering in a single day. To avoid instability problems solutions used in the certification of $\mathrm{M}_{\mathrm{w}}$ were prepared and measured on the same day. To test stability we conducted a second set of measurements on the same solutions a few days later. Of the two runs of SRM 2887 where stability was investigated, $\mathrm{M}_{\mathrm{w}}$ was seen to increase by a fraction of $2.2 \%$, or $1.9 \times 10^{+3} \mathrm{~g} / \mathrm{mol}$, and $4.4 \%$, or $3.8 \times 10^{+3} \mathrm{~g} / \mathrm{mol}$, when the solutions were stored at $130{ }^{\circ} \mathrm{C}$ as long as $2 \mathrm{~d}$ after preparation. We estimate that the light scattering data used in certification of SRM 
2887 were acquired within $12 \mathrm{~h}$ after the solutions were first heated. We take the factional contribution to the uncertainty due to changes during the first $12 \mathrm{~h}$ of heating to be at most $2 \%$, or $4.0 \times 10^{+3} \mathrm{~g} / \mathrm{mol}$. We take this to be our expanded uncertainty from this part of the measurement.

\subsubsection{Summary}

The combined expanded uncertainties, $\mathrm{U}_{\mathrm{c}}$, of SRM 2887 are computed as root-sum-of-squares of the component expanded uncertainties, $\mathrm{u}_{\mathrm{i}}$, following the formal NIST policy for evaluating and expressing uncertainty in measurements [16]. In Table 3, we find that the combined expanded uncertainty, $\mathrm{U}_{\mathrm{c}}$, of SRM 2887 is $13.7 \times 10^{+3} \mathrm{~g} / \mathrm{mol}$.

\subsection{Conclusions}

The $\mathrm{M}_{\mathrm{w}}$ of SRM 2887 by light scattering was determined to be $196.4 \times 10^{+3} \mathrm{~g} / \mathrm{mol}$ with a sample standard deviation of $6.6 \times 10^{+3} \mathrm{~g} / \mathrm{mol}$. A combined expanded uncertainty for this light scattering $\mathrm{M}_{\mathrm{w}}$ determination including all type $\mathrm{A}$ and type $\mathrm{B}$ uncertainties was $13.7 \times 10^{+3} \mathrm{~g} / \mathrm{mol}$. The intrinsic viscosity of SRM 2887 by solution viscosity in 1,2,4-trichlorobenzene was determined to be $276.9 \mathrm{~mL} / \mathrm{g}$ with a sample standard deviation of $2.5 \mathrm{~mL} / \mathrm{g}$. The standard deviation on the mean value was $0.4 \mathrm{~mL} / \mathrm{g}$. A combined expanded uncertainty for this intrinsic viscosity determination including all type A and type B uncertainties was $3.1 \mathrm{~mL} / \mathrm{g}$. The bottle-to-bottle variation of the SRM was check by size exclusion chromatography and found to be negligible.

\section{Acknowledgements}

The authors would like to thank Charles Han for the use of his high temperature light scattering instrument and his help and discussions concerning this project. Sachin Bhatt assisted with the limiting viscosity measurements. 


\section{Table 1}

Contributions to Expanded Uncertainty in Measured Intrinsic Viscosity of SRM 2887

\begin{tabular}{ll}
\hline \multicolumn{1}{c}{ Source of Uncertainty } & Uncertainty $(\mathbf{~ m L} / \mathbf{g})$ \\
\hline Shear rate dependence & 0.0 \\
\hline Solvent density, $\rho(0)$ & 0.6 \\
\hline Polymer specific volume, $v_{\mathrm{ve}}$ & 0.04 \\
\hline Buoyancy corrections & 0.0 \\
\hline Solute masses & 0.5 \\
\hline Solvent masses & 0.0 \\
\hline Timer & 0.1 \\
\hline Kinetic Energy correction factor & 0.8 \\
\hline Measurement temperature & 0.8 \\
\hline Sample uncertainty in fit of data & 2.5 \\
\hline Combined Expanded Uncertainties & 3.1 \\
\hline
\end{tabular}


Table 2

Contributions to Combined Expanded Uncertainty

Of the $\mathrm{M}_{\mathrm{w}}$ of SRM 2887

\begin{tabular}{lc}
\hline \multicolumn{1}{c}{ Source of Uncertainty } & $\begin{array}{c}\text { Contribution } \\
\left(\mathbf{1 0 ^ { + 3 }} \mathbf{g} / \mathbf{m o l}\right)\end{array}$ \\
\hline Expanded Uncertainty from standard deviation of the mean & 6.6 \\
\hline Solvent index of refraction & 0.2 \\
\hline Calibration of differential refractometer & 4.0 \\
\hline Differential refractive index & 5.6 \\
\hline Wavelength of light & $<0.1$ \\
\hline Rayleigh ratio of scattering standard, benzene & 7.8 \\
\hline Ratio Scattering Benzene to glass rod & 1.3 \\
\hline Temperature Dependence Glass Rod & 0.8 \\
\hline Ratio Scattering glass rod to TCB scattering standard & 0.8 \\
\hline Polarization of light & 3.4 \\
\hline Ratio of standard scattering to sample scattering & $<0.1$ \\
\hline Solvent density & 0.4 \\
\hline Solute and solvent masses & 0.4 \\
\hline Light reflection & $<0.1$ \\
\hline Instrumental misalignment & 2.0 \\
\hline Anisotropy of polymer in solution & $<0.1$ \\
\hline Truncation of virial expansion & 1.0 \\
\hline Scattering change during the scattering measurement & 4.0 \\
\hline & \\
\hline Combined expanded uncertainty ${ }^{*}, U_{c}$ & 13.7 \\
\hline * by root-sum-of-squares [16] &
\end{tabular}




\section{References}

[1] "Standard Practice for Dilute Solution Viscosity of Polymers" D2857-93, Annual Book of ASTM Standards, Vol 08.02 1995, ASTM, Philadelphia, PA.

[2] Peter H. Verdier and Herman L. Wagner, "The Characterization of Linear Polyethylene SRM's 1482, 1483, and 1484. I. Introduction" NBS Special Publication 260-61, P.H. Verdier and H.L. Wagner ed. December 1978 or National Bureau of Standards, Journal of Research, Vol. 83, No. 2, March - April, 1978, pg. 169-171.

[3] C. M. Guttman, J. R. Maurey and W. R. Blair, "Certification of the Relative Molecular Mass and the Limiting Viscosity of SRM 2886, a Polyethylene of Narrow Molecular Mass Distribution", NISTIR 6487, 2001.

[4] M. G. Natrella, "Experimental Statistics", National Bureau of Standards Handbook 91, U.S. Department of Commerce, 1963.

[5] Charles M. Guttman and John R. Maurey, "Recertification of Standard Reference Material 1475a, A Linear Polyethylene Resin", NISTIR 5199, 1993.

[6] L. Huber, "Application of the Diode-Array Detector in HPLC", Hewlett Packard, France, 08/89, pg. 89-100.

[7] Barry J. Bauer, Brian Dickens and William Blair, "Chromatographic Examination of Intaglio Inks, Resins and Varnishes", NISTIR 4949, 1991

[8] Charles M. Guttman, William R. Blair, John R. Maurey, "Recertification of SRM 1482a, a Polyethylene", NISTIR 6054, 1997.

[9] "PC-OMNITAB: An Interactive System for Statistical and Numerical Data Analysis, available from National Technical Information Service, Technology Administration, U.S. Department of Commerce, Springfield, VA 22161.

[10] See for example Howard W. Alexander "Elements of Mathematical Statistics", John Wiley \& Sons, 1961, pg. 165-170 or K. A. Brownlee "Statistical Theory and Methodology in Science and Engineering," John Wiley \& Sons, Inc., 1960, pg. 56.

[11] Richard G. Christensen, "The Characterization of Linear Polyethylene SRM 1475 V. Solution Viscosity Measurements" NBS Special Publication 260-42, H.L. Wagner and P.H. Verdier, Editors. September 1972 or National Bureau of Standards, Journal of Research, Vol. 76A, No. 2, March - April 1972,pg. 147-148. 
[12] Herman L. Wagner and Peter H. Verdier, "The Characterization of Linear Polyethylene SRM's 1482, 1483, and 1484. IV. Limiting viscosity number Numbers by Capillary Viscometry" NBS Special Publication 260-61, P.H. Verdier and H.L. Wagner ed. December 1978 or National Bureau of Standards, Journal of Research, Vol. 83, No. 2, March - April, 1978, pg. 195-201.

[13] "Operating Instructions for the Viscosity Measuring System AVS 400", Schott Gerate, Yonkers NY and Hofheim, Germany

[14] See for example F.W. Billmeyer, Jr, "Textbook of Polymer Science, 2nd edition", Wiley Interscience, NY (1971) pg 84.

[15] H. C. Booij, H. M. Schoffeleers and M. M. C. Haex, Macromolecules, 24, 3334-3339 (1991).

[16] B. N. Taylor and C. E. Kuyatt, "Guidelines for Evaluating and Expressing the Uncertainty of NIST Measurement Results." NIST Technical Note 1297, January 1993.

[17] A. Kruis, Z. Physik. Chem. B 34, 13-50 (1936).

[18] R. J. Anderson, Appl. Opt. $\underline{8}, 1508-1509$ (1969).

[19] LDC Analytical, "Instruction Manual for KMX-16 Laser Differential Refractometer" Section 5.3, "Calculation of Calibration Constant," Riviera Beach, FL, USA.

[20] H. L.Wagner and C.A.J.Hoeve, J. Poly. Science, Part A-2, 9, 1763-76 (1971). Although this is at a different wavelength we do not expect the overall variation to be wavelength dependent.

[21] J. Horska, J. Stejskal, and P. Kratochvil, "Refractive Increments of Polyolefins", J. Appl. Polym. Sci., Vol 28, p3873(1983)

[22] J. Horska, J. Stejskal, and P. Kratochvil, "Refractive Increments of Polyolefins", J. Appl. Polym. Sci., Vol 24, p1845(1979)

[23] J. A. Riddick and W. B. Bunger, "Organic Solvents, Phys. Properties and Methods of Purification," Wiley-Interscience, New York, 1970, Table 58, pg 145 or Table 30, pg 107. Also see B. L. Johnson and J. Smith, "Refractive Indices and Densities of Some Common Polymer Solvents," Ch. 2 in "Light Scattering from Polymer Solutions," Ed M. B. Huglin, Academic Press, London and NY (1972).

[24] "Instruction Manual for Laser Light Scattering Goniometers", Brookhaven Instrument Company, Ronkonkoma, New York, May 1984, catalog number BI-IM version 1.4 
[25] G. B. Arrowsmith, G. H. Jeffrey, and A. I. Vogel, J. Chem. Soc., pg 2072 (1965)

[26] H. L. Wagner, "The Characterization of Linear Polyethylene SRM 1475. VI. Differential Refractive Index of Polyethylene Solutions" NBS Special Publication 260-42, H.L. Wagner and P.H. Verdier, Editors. September 1972 or National Bureau of Standards, Journal of Research, Vol. 76A, No. 2, March - April, 1972, pg. 151-155

[27] W. Kaye and J. B. McDaniel, Appl. Opt., 13, 1934-1937 (1974).

[28] J. Ehl, C. Loucheux, C. Reiss, and H. Benoit, Makromol. Chem., 75, 35 (1964).

[29] Charles C. Han, Herman L. Wagner, and Peter H. Verdier, "The Characterization of Linear Polyethylene SRM's 1482, 1483, and 1484 III Weight-Average Molecular Weights by Light Scattering." NBS Special Publication 260-61, P.H. Verdier and H.L. Wagner ed. December 1978 or National Bureau of Standards, Journal of Research, Vol. 83, No. 2, March - April, 1978, pg. 185-193.

[30] H. Yamakawa, "Modern Theory of Polymer Solutions," Harper \& Row, N.Y., (1971).

[31] Charles M. Guttman, William R. Blair, John R. Maurey, "Recertification of SRM 706a, a Polystyrene", NISTIR 6091, 1998.

[32] "Instruction Manual for Laser Light Scattering Goniometers", Brookhaven Instrument Company, Ronkonkoma, New York, May 1984, catalog number BI-IM version 1.4

[33] H. Utiyama, "Calibration and Correction Factors," Ch. 4 in "Light Scattering from Polymer Solutions," Ed M. B. Huglin. pp 61-88, Academic Press, N.Y., (1972). 


\title{
National Institute of Standards \& Technology Certificate of Analysis
}

\author{
Standard Reference Material ${ }^{\circledR} 2887$
}

\author{
Polyethylene \\ $\left(\mathrm{M}_{\mathrm{w}}, 196400 \mathrm{~g} / \mathrm{mol}\right)$
}

This Standard Reference Material (SRM) is intended primarily for use in calibration and performance evaluation of instruments used to determine the molar mass ${ }^{*}$ and molar mass distribution by size exclusion chromatography. A unit of SRM 2887 consists of approximately $0.3 \mathrm{~g}$ of polyethylene powder. The certified values and uncertainties for massaverage molar mass and intrinsic viscosity are presented in Table 1.

Table 1. Certified Properties

\section{Property}

Mass-Average Molar Mass ${ }^{*}\left(\mathrm{M}_{\mathrm{w}}\right)$

Intrinsic Viscosity [ $\eta]$ in

1,2,4-trichlorobenzene at $130{ }^{\circ} \mathrm{C}$

*Previously expressed as molecular weight [1].
Certified Value

$196.4 \times 10^{3} \mathrm{~g} / \mathrm{mol} \pm 13.7 \times 10^{3} \mathrm{~g} / \mathrm{mol}$

$276.9 \mathrm{~mL} / \mathrm{g} \pm 3.1 \mathrm{~mL} / \mathrm{g}$

Certified Values and Uncertainties: The certified value for $\mathrm{M}_{\mathrm{w}}$ was originally measured using static light scattering with 1-chloronaphthalene as the solvent at $130^{\circ} \mathrm{C}$ [3]. The certified value for the intrinsic viscosity was determined in 1,2,4-trichlorobenzene at $130{ }^{\circ} \mathrm{C}$.

The certified measurement uncertainty is expressed as a combined expanded uncertainty with a coverage factor, $k=2$, calculated in accordance with NIST procedure [2]. Type A and Type B contributions to the expanded uncertainty of the measured mass-average molar mass include the uncertainties in the Rayleigh ratio of the scattering standard, optical alignment, and calibration of the differential refractometer.

Expiration of Certification: The certification of SRM 2887 is valid until 01 January 2008, within the measurement uncertainties specified, provided that the SRM is handled in accordance with the storage instructions given in this certificate. This certification is nullified if the SRM is modified or contaminated.

Maintenance of SRM Certification: NIST will monitor this SRM over the period of its certification. If substantive technical changes occur that affect the certification before expiration of this certificate, NIST will notify the purchaser. Return of the attached registration card will facilitate notification.

The technical coordination leading to certification of this SRM was provided by B.M. Fanconi of the NIST Polymers Division. Technical measurement and data interpretation were provided by C.M. Guttman, W.R. Blair, J.R. Maurey, and C.R. Schultheisz of the NIST Polymers Division.

The support aspects involved in the preparation, certification, and issuance of this SRM were coordinated through the NIST Standard Reference Materials Program by J.W.L. Thomas.

Eric J. Amis, Chief Polymers Division

Gaithersburg, MD 20899

Nancy M. Trahey, Chief

Certificate Issue Date: 06 April 2001

Standard Reference Materials Program 
Storage: The SRM should be stored in the original bottle with the lid tightly closed and under normal laboratory conditions.

Homogeneity and Characterization: The homogeneity of SRM 2887 was tested by size exclusion chromatography analysis of solutions in 1,2,4-trichlorobenzene at $130{ }^{\circ} \mathrm{C}$. The characterization of this polymer is described in Reference 3. SRM 2887 is the result of a clean-up, blending, and rebottling of the fractionation of SRM 1475. It was produced in the same fractionation as SRM 1482, SRM 1483 and SRM 1484 [4].

\section{REFERENCES}

[1] Taylor, B.N., "Guide for the Use of the International System of Units (SI)," NIST Special Publication 811, 1995 Ed., (April 1995).

[2] Guide to the Expression of Uncertainty in Measurement, ISBN 92-67-10188-9, 1st Ed. ISO, Geneva, Switzerland, (1993): see also Taylor, B.N. and Kuyatt, C.E., "Guidelines for Evaluating and Expressing the Uncertainty of NIST Measurement Results,” NIST Technical Note 1297, U.S. Government Printing Office, Washington DC, (1994); available at http://physics.nist.gov/Pubs/.

[3] Guttman, C.M., Maurey, J.R., and Blair, W.R., "Certification of the Relative Molecular Mass and the Intrinsic Viscosity of SRM 2887, a Polyethylene of Narrow Molecular Mass Distribution,” NISTIR 6456.

[4] Verdier, P.H. and Wagner, H.L., "The Characterization of Linear Polyethylene SRM's 1482, 1483, and 1484, I. Introduction," NBS Special Publication 260-61, (December 1978); or National Bureau of Standards, Journal of Research, 83, No. 2, pp. 169-171, (1978).

Users of this SRM should ensure that the certificate in their possession is current. This can be accomplished by contacting the SRM Program at: telephone (301) 975-6776; fax (301) 926-4751; e-mail srminfo@nist.gov; or via the Internet http://www.nist.gov/srm. 